\title{
Lenticulostriate vasculopathy in preterm infants: a new classification, clinical associations and neurodevelopmental outcome
}

\author{
Julide Sisman $^{1} \cdot$ Lina Chalak ${ }^{1} \cdot$ Roy Heyne ${ }^{1} \cdot$ Marcia Pritchard $^{2} \cdot$ Devri Weakley $^{2} \cdot$ L. Steven Brown ${ }^{3}$. \\ Charles R. Rosenfeld (10) ${ }^{1}$
}

Received: 30 May 2018 / Revised: 30 May 2018 / Accepted: 6 August 2018 / Published online: 16 August 2018

(c) Springer Nature America, Inc. 2018

\begin{abstract}
Objective To examine the inter-rater reliability for the diagnosis of LSV on cranial ultrasound (cUS), determine the risk factors associated with LSV and its progression, and examine neurodevelopmental outcome.

Study design Prospective case-control study of neonates $\leq 32 \mathrm{wks}$ of gestation assessed for LSV by serial cUS $(n=1351)$ between 2012 and 2014 and their neurodevelopment at 18-36mon-corrected age compared to controls.

Results Agreement for LSV on cUS improved from Kappa 0.4-0.7 after establishing definitive criteria and guidelines. BPD was the only variable associated with the occurrence and the progression of LSV. Cytomegalovirus (CMV) infection occurred in one neonate $(1.5 \%)$. Neurodevelopmental outcome of neonates with LSV did not differ from controls.

Conclusions Establishment of well-defined stages of LSV improves the reliability of the diagnosis and allows identification of neonates with progression of LSV. Although LSV was associated with BPD, it was not associated with congenital CMV infection.
\end{abstract}

\section{Introduction}

Lenticulostriate vasculopathy (LSV) was first reported 30 yrs ago on a cranial ultrasound (cUS) obtained on a preterm neonate with congenital cytomegalovirus (CMV) infection. These hyperechogenic lines within the deep gray matter were located in the area of lenticulostriate vessels and differed from the clumped shadowing echogenicities associated with calcifications [1]. Teele et al. subsequently

Electronic supplementary material The online version of this article (https://doi.org/10.1038/s41372-018-0206-8) contains supplementary material, which is available to authorized users.

Julide Sisman

julide.sisman@utsouthwestern.edu

1 Department of Pediatrics, Division of Neonatal-Perinatal Medicine, University of Texas Southwestern Medical Center, Dallas, TX, USA

2 Department of Radiology, University of Texas Southwestern Medical Center and Children's Health System of Texas, Dallas, TX, USA

3 Department of Health System Research, Parkland Health and Hospital System, Dallas, TX, USA published the first retrospective case series of 12 neonates with LSV [2]. Eight of the neonates had evidence of congenital TORCH infections (toxoplasma, others, rubella, cytomegalovirus, and herpes). In the following years, LSV became synonymous with the presence of congenital infection. However, in more recent studies numerous noninfectious etiologies have been observed to be associated with the presence of LSV on cUS, including hypoxicischemic events, chromosomal anomalies, inborn errors of metabolism, fetal alcohol exposure, and congenital anomalies [3]. Thus, the pathogenesis of LSV remains unclear.

The presence of LSV is best determined by cUS. Neither computerized axial tomography nor magnetic resonance imaging have consistently demonstrated corresponding abnormalities when hyperechogenic lines were detected in the supratentorial deep gray matter structures by cUS [4-7]. Doppler blood flow studies subsequently demonstrated arterial signals within the hyperechogenic lines in the basal ganglia and thalamus, supporting the view that LSV represents a vascular lesion [4, 8-12]. Although LSV is best detected by cUS, the radiographic definition is vague and inter-rater reliability has generally been poor [13]. Thus, the presence of "hyperechogenic lines in the basal ganglia and/ 
or thalamus" may be insufficient following the technological advances in cUS imaging, which demonstrate an enhanced pattern of echos and may result in false positive conclusions. These advances may also enhance detection of LSV and allow for studies of the progression of LSV after birth; but this would require a better definition of the changes in echogenicity that occur.

The primary aim of this prospective case-control study was to evaluate the inter-rater reliability of cUS recognition of LSV among pediatric radiologists and determine if this could be improved after implementing a predefined standardized classification of LSV. In addition, we sought to assess the incidence of LSV, determine the association with congenital CMV infection, examine if LSV is associated with specific clinical risk factors, and determine if LSV is associated with altered neurodevelopment in preterm neonates $\leq 32 \mathrm{wks}$ gestational age (GA).

\section{Methods}

This is a prospective case-control study of neonates $\leq 32 \mathrm{wks}$ GA admitted to the Neonatal Intensive Care Unit (NICU) at Parkland Hospital, Dallas, TX between January 2012 and June 2014. The study was approved by the Institutional Review Board of the University of Texas Southwestern Medical Center and Parkland Health and Hospital Systems. Parental consent was obtained prior to enrollment. All neonates $\leq 32 \mathrm{wks}$ GA admitted to the NICU have cUS scans at 3-5 days (and/or 7-10 days) and 30-day postnatal and at discharge [14]. They are performed by skilled ultrasound technicians using the Siemens Acuson Sequoia 512 Ultrasound systems with high frequency $8 \mathrm{~Hz}$ transducer. Standard coronal and sagittal images were obtained from the anterior fontanel. Mastoid views were obtained through the posterior fontanel. All of the cUS were prospectively reviewed for the presence of LSV by a team of pediatric radiologists assigned to the NICU. To assess the variance in readings, we established three readers. Reader A included "all" of the radiologists who routinely evaluated cUS on a daily basis ( $n=9$ physicians that include both study radiologists); Reader B was the study radiologist (MP), who prospectively evaluated all cUS for absence or presence of LSV; Reader C was another study radiologist (DW), who independently evaluated the cUS when there was a disagreement between the Readers A and B or if Readers A and $\mathrm{B}$ were the same reader in order to establish a consensus. Both study radiologists were blinded to the interpretations of the all other radiologists, including each other. The diagnosis of LSV was based on the recognition of a lesion defined as "hyperechogenic lines within the basal ganglia and/or thalamus on both coronal and parasagittal views on cranial ultrasound". All neonates identified to have
LSV by either Reader A or B were included in the study. Neonates were excluded if a consensus was not established by at least two radiologists (Readers A and B, Readers B and $\mathrm{C}$, or Readers $\mathrm{A}$ and $\mathrm{C}$ ). In order to establish a more standardized and consistent method for determining the presence of LSV and assessing its extent, we introduced a new grading system for LSV in February 2013 (Fig. 1): Stage 0 had no hyperechoic lines/vessels; Stage 1 included the presence of lenticulostriate vessels that were considered thin and faintly seen; Stage 2 included vessels that were considered thin, but hyperechogenic; and Stage 3 included vessels that were considered thick and hyperechogenic, i.e., the echogenicity resembled that seen in the Sylvian fissure. All the cUS of neonates with LSV obtained prior to February 2013 were blindly re-evaluated by Readers B and C and the new classification system used to assign staging and assess the progression of LSV. The highest stage LSV agreed on by at least two radiologists was then used to subsequently group the neonates for severity of LSV.

In order to determine what clinical data are associated with the presence and/or progression of LSV on cUS, we prospectively collected the following data: prenatal risk factors including maternal age, race, ethnicity and gravida, multiple births, maternal drugs used in pregnancy, maternal diabetes and hypertension. Additional risk factors included administration of antenatal steroids, maternal chorioamnionitis, prolonged rupture of membranes $>18 \mathrm{~h}$, any fetal distress, meconium stained amniotic fluid, mode of delivery and exposure to intrapartum magnesium sulfate. Postnatal risk factors included birth weight (BW), head circumference, GA, gender, Apgar scores and umbilical artery $\mathrm{pH}$, base excess, and $\mathrm{PaO}_{2}$, and admission temperature. Preterm infants who were small for gestational age (SGA) or had a birth weight $<25$ th centile were identified as a potential proxy for chronic intrauterine hypoxia [15]. Neonatal morbidity was also assessed and included: respiratory distress syndrome (RDS), symptomatic patent ductus arteriosus, congenital and acquired pneumonia, transient tachypnea of newborn, pulmonary artery hypertension, pulmonary hemorrhage, apnea of prematurity, sepsis, necrotizing enterocolitis (NEC; only Stage 2 and 3), bronchopulmonary dysplasia (BPD), pulmonary interstitial emphysema, pneumothorax, surfactant administration, inhaled nitric oxide administration, number of ventilator days, sepsis, retinopathy of prematurity, ICH, PVL, VM, neonatal hypoxic encephalopathy, and hypothyroidism (defined as if treatment was required). The presence of congenital CMV infection was determined by maternal serology and urine CMV cultures obtained at the time of first cUS with LSV. Evaluation of congenital infections in the control neonates was limited to maternal serology or presence of clinical manifestations. None of the control patients showed clinical stigmata of CMV infection. 
Fig. 1 Proposed classification for staging LSV on parasagittal cUS in the neonate. a Stage 0: Lenticulostriate vessels are not visible on gray scale image. b Stage 1: Faint linear echogenicities corresponding to a lenticulostriate artery (arrow). c Stage 2: Thin hyperechogenic lenticulostriate vessels (arrows). d Stage 3: Lenticulostriate vessels are thick (solid arrows) and echogenicity equals sulci (dashed arrow)
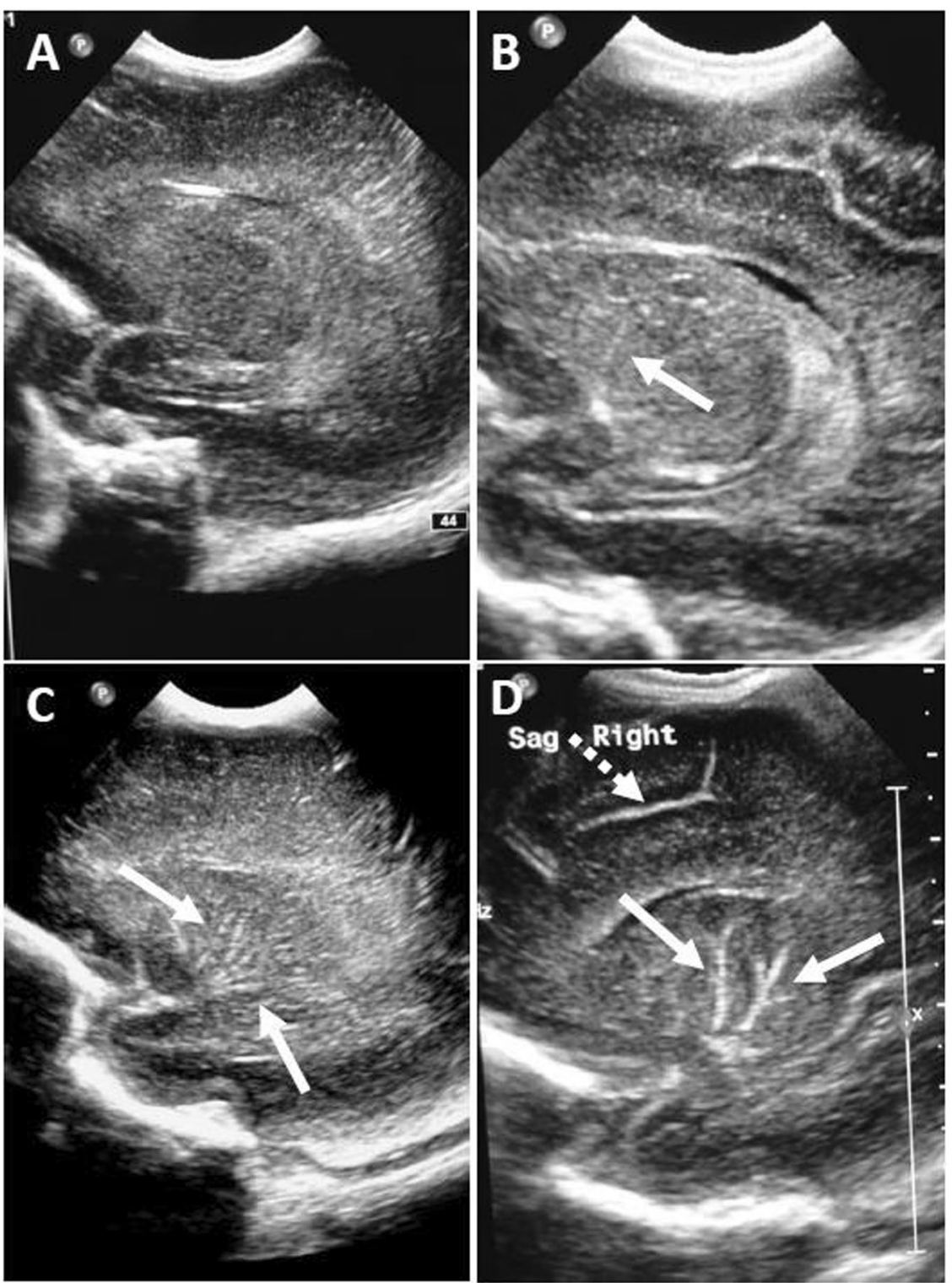

All neonates enrolled in the study were scheduled for follow-up and neurodevelopmental assessment at 18-36mon adjusted age in the Thrive Clinic at the Children's Medical Center at Dallas. Infants were classified as having neurodevelopmental impairment (NDI) based on the Bayley Scales of Infant and Toddler Development (BSID) version III, which is assessed at 18-36mon-adjusted age. The Bayley III threshold for moderate-to-severe NDI was defined as having a cognitive composite score $>1$ SD below the mean $(<85)$ and/or a motor composite score $<73$. The latter threshold was based on data from the Neonatal Research Network, which demonstrated that $<73$ was more sensitive and specific for detecting moderate-to-severe gross and/or fine motor impairment than a cutoff of $<85$, though the latter had been shown to be better for cognitive [16]. In order to have a comparison group, we also enrolled GA and gender matched controls. We matched each infant with LSV 1:1 with the next infant born following who had the same GA (completed weeks of gestation) and gender without evidence of LSV, intracranial hemorrhage (ICH), periventricular leukomalacia (PVL), or ventriculomegaly (VM) on any of the cUS scans by discharge.

\section{Statistical analysis}

Statistical analyses were performed using SPSS software version 19. We calculated the sample size based on incidence estimate and precision. A sample size of 360 would need to be evaluated assuming a LSV incidence of 5-20\% or 18-72 infants with LSV with a narrow $95 \%$ confidence 
Table 1 Kappa analysis comparing the readings of cranial ultrasound scans for the absence and presence of lenticulostriate vasculopathy by Readers A and B and then Reader B and C before and after implementation of the new classification

\begin{tabular}{lllll}
\hline & Before & \multicolumn{3}{c}{ After } \\
\hline & Reader B & \multicolumn{3}{c}{ Reader B } \\
Reader A & Absent & Present & Absent & Present \\
Absent & 589 & 46 & 583 & 45 \\
Present & 2 & 22 & 0 & 64 \\
Kappa & $0.44(95 \%$ CI: & 0.70 (95\% CI: \\
& $0.32-0.57)$ & $0.62-0.78)$ & \\
& Reader C & Reader C & \\
Reader B & Absent & Present & Absent & Present \\
Absent & 48 & 4 & 2 & 0 \\
Present & 13 & 55 & 0 & 62 \\
Kappa & $0.71(95 \%$ CI: & $1.00(95 \%$ CI: 1.00, \\
& $0.59-0.84)$ & $1.00)$ & \\
\hline
\end{tabular}

Reader A represents the group interpretations, whereas Readers B and $\mathrm{C}$ are independent readers

interval (half width of 2-4\%). Kappa statistics were used to assess inter-rater reliability between the three readers described above. Kappa $>0.20$ is considered to be "fair" agreement, 0.40 "moderate" agreement, 0.60 "good" agreement and $>0.80$ "excellent" agreement [17]. Categorical variables were analyzed by $\chi^{2}$ analysis and continuous variables for multiple groups by analysis of variance (ANOVA). If the ANOVA had a $P<0.05$, differences between groups were determined using pairwise analysis and a Bonferroni correction method. Logistic regression analysis was conducted to examine the relationships between stages of LSV and NDI. Multinomial logistic regression analysis with forward selection of variables that could be associated with occurrence or progression of LSV (GA, BW $<10$ th and $<25$ th centile, cesarean delivery, male gender, multiple birth, maternal chorioamnionitis, antenatal steroids, Apgar scores, RDS, BPD, apnea, NEC and hypothyroidism) was performed in order to identify the variables that predict the occurrence and/or progression of LSV. Variables are summarized as percentages and means \pm standard deviation (SD). All statistical tests used a significance level of 0.05 .

\section{Results}

\section{Validation of cUS readings}

Total of 445 neonates $\leq 32 \mathrm{wks}$ GA were admitted to the NICU during the study period. Four hundred and seven had at least one cUS performed. Of the 407 neonates studied, there were 1351 cUS available for evaluation. LSV was identified in 70/407 neonates by either Reader A or B on at least one cUS; the agreement by both readers was $50 / 70$ (71\%). Reader C evaluated the remaining 20 neonates' cUS and LSV confirmed in 15; thus incidence of LSV on cUS in neonates $\leq 32$ wks GA was $15 \%(65 / 407)$.

Of the 1351 cUS available, 659 cUS were obtained prior to introducing the new classification. Seventy (11\%) cUS were read as positive for LSV by Readers A and B. There was disagreement on 48 resulting in a Kappa of 0.44 (Table 1). In contrast, there was good inter-rater reliability between Readers B and C, who agreed on the presence of LSV on 55 cUS, absent on 48 and disagreed on 17, Kappa 0.71 (Table 1). After implementing the new classification for LSV on cUS in February 2013, there were 692 cUS available for review. Of these, 109 (16\%) had a least one reading positive for LSV. Readers A and B agreed 64/109 were positive for LSV and disagreed on $45 \mathrm{cUS}$. Importantly, the Kappa improved to 0.70 (Table 1), while the agreement between Readers B and C improved to $100 \%$.

\section{Clinical variables associated with LSV}

In order to assess the clinical variables associated with the occurrence of LSV on cUS, we divided the study neonates into four groups according to their highest stage of LSV: Stage 0 included the controls, none of whom had LSV, and LSV Stage 1, 2, or 3 included neonates as defined above. Groups did not differ from each other for any of the variables examined (Table 2). However, when a stepwise regression analysis was performed, BPD was associated with the occurrence of $\operatorname{LSV}[P=0.02$; odds ratio $(\mathrm{OR})=$ $2.9 ; 95 \% \mathrm{CI}=1.1-7.2]$. Four of the 135 infants studied (65 LSV and 70 control) died, all had LSV; 3 died from severe BPD and 1 with $E$. coli sepsis. Urine CMV cultures were performed in $98 \%(64 / 65)$ of neonates with LSV at the time of initial cUS diagnosis, mean postnatal age of 18 days (95\% CI $=15-22 \mathrm{~d}$ ). Only one $(1.5 \%)$ of these neonates tested positive for congenital CMV infection and the neonate was at $7 \mathrm{~d}$ postnatal age.

\section{Onset and progression of LSV}

We assessed the age at first diagnosis and if there was progression of LSV after birth. Neonates with Stage 1 LSV $(n=22)$ were more likely to be diagnosed after $15 \mathrm{~d}$ postnatal, the incidence increasing from $13 \%$ at $1-4 \mathrm{~d}$ to $74 \%$ after $15 \mathrm{~d}$ (mean $27 \mathrm{~d}$; 95\% CI $=19-35 \mathrm{~d})$. Stage $2(n=31)$ and Stage $3(n=12) \mathrm{LSV}$ were more likely to be first observed on cUS at an earlier age (mean 14d; $95 \% \mathrm{CI}=$ $11-18 d$ ), with $60 \%$ presenting $<15$ d postnatal and $40 \%$ after 15d $\left(P=0.04, \chi^{2}\right)$ (Fig. 1, Supplementary material).

We were able to evaluate the progression of LSV on 248 serial cUS (mean number of cUS for each neonate was 
Table 2 Maternal and neonatal demographics and clinical characteristics associated with the different stages of lenticulostriate vasculopathy determined from the highest stage diagnosed

\begin{tabular}{|c|c|c|c|c|c|}
\hline & $\begin{array}{l}\text { Control } \\
(n=70)\end{array}$ & $\begin{array}{l}\text { Stage 1 } \\
(n=22)\end{array}$ & $\begin{array}{l}\text { Stage 2 } \\
(n=31)\end{array}$ & $\begin{array}{l}\text { Stage } 3 \\
(n=12)\end{array}$ & $P$ value $\mathrm{c}^{\mathrm{c}}$ \\
\hline Maternal age (yrs) & $28 \pm 7^{\mathrm{a}}$ & $29 \pm 7$ & $31 \pm 8$ & $27 \pm 8$ & 0.2 \\
\hline Race/ethnicity & & & & & 0.33 \\
\hline $\begin{array}{l}\text { White Non- } \\
\text { Hispanic }\end{array}$ & $8(11)^{b}$ & $1(5)$ & $2(7)$ & $1(8)$ & \\
\hline $\begin{array}{l}\text { Black Non- } \\
\text { Hispanic }\end{array}$ & $8(11)$ & $6(27)$ & $4(13)$ & $5(33)$ & \\
\hline Hispanic & $54(77)$ & $15(68)$ & $25(80)$ & $7(58)$ & \\
\hline Maternal diabetes & $12(17)$ & $1(5)$ & $4(13)$ & $0(0)$ & 0.23 \\
\hline $\begin{array}{l}\text { Maternal } \\
\text { hypertension }\end{array}$ & $29(41)$ & $8(36)$ & $13(42)$ & $1(8)$ & 0.17 \\
\hline Chorioamnionitis & $5(7)$ & $1(5)$ & $3(10)$ & $1(8)$ & 0.92 \\
\hline Antenatal steroids & $33(47)$ & $14(64)$ & $11(36)$ & $9(75)$ & 0.06 \\
\hline Magnesium exposure & $33(47)$ & $9(41)$ & $15(48)$ & $2(17)$ & 0.24 \\
\hline Cesarean delivery & $56(80)$ & $16(73)$ & $24(77)$ & $8(67)$ & 0.73 \\
\hline Gestational age (wk) & $29 \pm 2$ & $29 \pm 2$ & $30 \pm 2$ & $29 \pm 3$ & 0.83 \\
\hline Birth weight (g) & $\begin{array}{l}1221 \pm \\
263^{\mathrm{a}}\end{array}$ & $\begin{array}{l}1187 \pm \\
319^{\mathrm{a}}\end{array}$ & $\begin{array}{l}1340 \pm \\
378^{\mathrm{a}}\end{array}$ & $\begin{array}{l}1459 \pm \\
540^{\mathrm{a}}\end{array}$ & 0.05 \\
\hline $\begin{array}{l}\text { Birth weight } \leq 10 \text { th } \\
\text { centile }\end{array}$ & $11(15)$ & $4(18)$ & $4(13)$ & $1(8)$ & 0.87 \\
\hline $\begin{array}{l}\text { Birth weight }<25 \% \\
\text { centile }\end{array}$ & $26(37)$ & $7(32)$ & $9(29)$ & $2(16)$ & 0.53 \\
\hline Male & $31(44)$ & $8(35)$ & $14(47)$ & $5(42)$ & 0.84 \\
\hline Umbilical artery $\mathrm{pH}$ & $\begin{array}{l}7.26 \pm \\
0.08\end{array}$ & $\begin{array}{l}7.25 \pm \\
0.09\end{array}$ & $\begin{array}{l}7.22 \pm \\
0.10\end{array}$ & $\begin{array}{l}7.27 \pm \\
0.08\end{array}$ & 0.20 \\
\hline $\begin{array}{l}\text { Umbilical artery base } \\
\text { deficit }\end{array}$ & $-6 \pm 3.2$ & $-6 \pm 3.8$ & $-7 \pm 4.6$ & $\begin{array}{l}-5.6 \pm \\
2.6\end{array}$ & 0.37 \\
\hline RDS & $47(67)$ & $16(73)$ & $22(71)$ & $9(75)$ & 0.92 \\
\hline BPD & $10(14)$ & $5(23)$ & $9(29)$ & $4(33)$ & 0.23 \\
\hline NEC & $0(0)$ & $0(0)$ & $2(7)$ & $0(0)$ & 0.21 \\
\hline HIE & $0(0)$ & $0(0)$ & $1(3)$ & $0(0)$ & 0.34 \\
\hline ROP & $19(27)$ & $7(32)$ & $5(16)$ & $4(33)$ & 0.50 \\
\hline Hypothyroidism & $2(3)$ & $2(9)$ & $2(7)$ & $2(17)$ & 0.25 \\
\hline Congenital CMV & NA & $0(0)$ & $0(0)$ & $1(1)$ & 0.11 \\
\hline PVL & NA & $3(14)$ & $3(10)$ & $0(0)$ & 0.42 \\
\hline ICH & NA & $4(18)$ & $8(26)$ & $4(33)$ & 0.61 \\
\hline Mortality & NA & $1(5)$ & $1(3)$ & $2(17)$ & 0.24 \\
\hline
\end{tabular}

$R D S$ respiratory distress syndrome, $B P D$ bronchopulmonary dysplasia, $N E C$ necrotizing enterocolitis, HIE hypoxic-ischemic encephalopathy, $C M V$ cytomegalovirus, $P V L$ periventricular leukomalacia, $I C H$ intracranial hemorrhage

${ }^{\mathrm{a}}$ Values are presented as means $\pm \mathrm{SD}$

${ }^{b}$ Values in parentheses are the percent of the total population within a column

${ }^{c}$ Data analyzed by ANOVA for continuous variables and $\chi^{2}$ for categorical variables. When ANOVA was $P<0.05$, Bonferroni's pairwise analysis was performed to separate groups; significant differences between groups across rows are noted by different superscripts

3.8; 95\% CI $=3.6-4.1)$. This included all neonates with LSV. Sixty-seven percent of neonates (44/65) with LSV showed progression from Stage 0: 19 neonates from Stage 0 to 1,18 neonates from Stage 0 to 2 and 7 neonates from Stage 0 to 3 . When we compared neonates who progressed from Stage 0 to 1,2 , or 3 to control neonates, those progressing to Stage 2 were more likely to have BPD ( $P=$ $0.02)$, NEC $(P=0.02)$ and infants progressing to Stage 3 were more likely to have hypothyroidism $(P=0.04$, ANOVA). (Table 1, Supplementary material). BPD was the only clinical variable associated with LSV progression from Stage 0 to $2(P=0.003 ; \mathrm{OR}=7 ; 95 \% \mathrm{CI}=1.9-25)$ by multinomial logistic regression analysis; progression to Stage 3 was not significant due to the small number of neonates $(n=7 ; P=0.1, \mathrm{OR}=3.6 ; 95 \% \mathrm{CI}=0.6-20)$.

\section{Neurodevelopmental outcome}

Forty infants with LSV (66\%) completed follow-up at 18-36mon-corrected age; 4 died before discharge, 8 were seen before 18 mon, and 13 were lost to follow-up. Twenty-nine of the 40 infants had isolated LSV with no evidence of ICH, PVL, or VM on cUS while 11 had LSV Plus (LSV with ICH, PVL, or VM) (Table 3). When these two groups were compared to the 48 control infants who were seen at 18-36mon-corrected age (48/70, 69\%), there were no significant differences for any measurement of neurodevelopment outcome between the three groups (Table 3). We also determined if the 40 infants with LSV who completed follow-up differed from the 21 infants who were either lost to follow-up or seen before 18 mon. There were no significant differences in any of the demographics or clinical variables, except those who completed follow-up had lower birth weight $(P=0.01)$ and GA $(P<0.01)$. When the risk for NDI was classified by the stage of LSV and assessed by logistic regression analysis, there were no significant differences between Stage $1(\mathrm{OR}=0.54,95 \% \mathrm{CI}=0.17,1.71)$ or Stages $2+$ $3(\mathrm{OR}=1.52,95 \% \mathrm{CI}=0.61,3.78) \mathrm{LSV}$ and controls (Table 2, Supplementary material).

\section{Discussion}

Although LSV has been observed on cUS in preterm neonates by numerous investigators, important gaps of knowledge remain regarding validation of the cUS readings, progression on serial cUS and its effects on NDI at followup. Moreover, it remains unclear what factors are associated with the diagnosis of LSV on cUS. This is the first prospective study that not only provides a classification for neonatal LSV and its validation, but also examines the staging and progression of LSV as well as the neurodevelopmental outcomes in a contemporary cohort of preterm infants. The key observations are: (1) improved reliability of LSV diagnosis after establishing a well-defined classification of LSV on cUS, (2) strong association between BPD with LSV, (3) progression of LSV in preterm neonates with inflammatory diseases such as BPD and NEC, and (4) 
Table 3 Comparison of neurodevelopmental outcomes in control preterm neonates, those with isolated lenticulostriate vasculopathy, and lenticulostriate vasculopathy plus other abnormalities on cranial ultrasound

\begin{tabular}{lllll}
\hline & $\begin{array}{l}\text { Control } \\
(\mathrm{n}=48)\end{array}$ & $\begin{array}{l}\text { Isolated LSV } \\
(\mathrm{n}=29)\end{array}$ & $\begin{array}{l}\text { LSV Plus } \\
(\mathrm{n}=11)\end{array}$ & $P$ value $^{\mathrm{a}}$ \\
\hline BSID mean chronologic age & $2.3 \pm 0.5$ & $2.3 \pm 0.4$ & $2.3 \pm 0.4$ & 0.97 \\
BSID mean corrected age & $2.2 \pm 0.5$ & $2.1 \pm 0.4$ & $2.1 \pm 0.4$ & 0.68 \\
Cognitive composite score & $84 \pm 9$ & $83 \pm 9$ & $89 \pm 8$ & $0.21\left(0.3^{\mathrm{b}}\right)$ \\
Motor composite score & $90 \pm 8$ & $89 \pm 9$ & $91 \pm 9$ & $0.76\left(0.75^{\mathrm{b}}\right)$ \\
Cognitive composite score $<85$ & $19(39)^{\mathrm{c}}$ & $14(48)$ & $3(27)$ & 0.46 \\
Motor composite score $<73$ & $1(2)$ & $1(3)$ & $0(0)$ & 0.81 \\
NDI (cognitive $<85$ or motor $<73)$ & $19(39)$ & $14(48)$ & $3(30)$ & 0.55 \\
\hline
\end{tabular}

${ }^{\mathrm{a} O n e-w a y ~ A N O V A}$

${ }^{\mathrm{b}}$ Two-way ANOVA $P$ value adjusted for BSID examination age

${ }^{c}$ Values in parenthesis are percent of total within a column neurodevelopmental outcomes that do not differ from preterm controls.

Early reports suggested that the incidence of LSV in preterm neonates was on the order of $0.02-5 \%$ [8, 18-23]. More recently, it has been suggested that the incidence has increased and now ranges from 10-32\% [7, 24, 25]. In our study, the incidence of LSV after validation of the cUS interpretation was $15 \%$ in neonates $<32$ wks GA, suggesting the incidence may have increased in recent years. However, it is possible that improved ultrasound technology and increased awareness of this condition have contributed to the increased identification of neonates with LSV. Alternatively, the definitions of LSV on cUS might have been inadequate in the past.

Numerous investigators have consistently agreed that the lenticulostriate arteries are not normally visualized on cUS $[2,8,21]$. However, interpretation of echogenicity is often subjective; thus, consensus readings are essential to enhancing the diagnostic confidence [26, 27]. There are few reported studies that confirm the diagnosis of LSV by another reader and thus demonstrate validation [19, 28]. We previously reported in a retrospective study that Kappa values were quite low for the presence of LSV on cUS, 0.18 for cUS at $1-4 \mathrm{~d}, 0.33$ at $5-14 \mathrm{~d}$, and 0.36 at $>15 \mathrm{~d}$ postnatal, and showed no improvement with postnatal age [13]. El Ayoubi and Shin et al. generated a staging system for LSV on the basis of number of the "echogenic stripes [6, 29]. Although, this classification might be useful, the echogenicity and the thickness of the linear stripes were not included. More recently, Hong et al. measured the diameter of the affected vessel and used $2.5 \mathrm{~mm}$ as the cutoff for stage mild vs. severe LSV, but it was unclear why $2.5 \mathrm{~mm}$ was used as cutoff [30]. Nonetheless, the pattern of LSV recognition was retrospective without validation in all of these studies and there were no serial cUS analyzed to examine progression. The diagnosis of LSV can be operator dependent, suggesting that the current definitions of LSV may be inadequate in light of the advanced cUS technology.
Therefore, we developed a new classification for LSV transitioning from faint visibility to increased echogenicity and to increased echogenicity plus thickness to reflect our observations for "developing vasculopathy". Importantly, we confirmed that the diagnostic agreement for LSV on cUS among a group of pediatric radiologists significantly improved after establishing the new classification. We strongly suspect that the lack of uniform diagnostic criteria has been a major contributor to the variability of the diagnosis among radiologists, which likely confounded the true incidence of LSV.

Hypoxic/ischemic conditions are reported to be the leading cause of LSV in several retrospective cohort studies and case series [8, 9, 18, 21, 31, 32]. However, case-control studies have failed to show a significant association between hypoxic/ischemic conditions and LSV [7, 19, 22, $23,28]$. In a recent retrospective case-control study, it was observed that isolated late onset LSV (seen on cUS $>5 \mathrm{~d}$ postnatal) was associated with younger GA, lower BW and the presence of BPD [33]. We also observed that BPD was associated with the occurrence of LSV, but found no relation with GA or BW. However, BPD and NEC, which are associated with systemic inflammatory responses, were associated with the progression of LSV in the postnatal period. This could relate to the neutrophil and macrophage influx as well as increased levels and expression of proinflammatory cytokines such as IL-8, TNF $\alpha$, IL-1, and IL-6 found in the tracheal aspirates of neonates who subsequently developed BPD [34-37]. Similarly, histological sections of intestine from preterm infants with NEC show ischemia with inflammation [38], which is associated with increased levels of circulating cytokines [39, 40]. It is notable that the smaller deep penetrating arteries of the brain are particularly susceptible to hypoxic-ischemic injury [41, 42] and infection [3]. Thus, inflammation may represent a common pathway to the development and progression of vasculitis in the lenticulostriate arteries, explaining the deposition of granular, basophilic material on 
histopathology that was previously described in the brains of neonates with LSV $[2,8,9]$.

Robust evidence now exists that non-infections causes of LSV may be more common than congenital infections [7, 8, $18,21,32]$. In earlier reports there was an association between LSV and congenital infection, in particular CMV [1, 2, 4, 43-46]. More recently, this has been questioned [7, $32,33]$. We obtained urine CMV cultures from $98 \%$ of the neonates with LSV at the time of diagnosis, but only one neonate tested positive for congenital CMV infection. This occurred in a $32 \mathrm{wks}$ GA neonate who had Stage 3 LSV on the first cUS obtained at $7 \mathrm{~d}$ postnatal and remained Stage 3 throughout the hospitalization. Thus, congenital infection may account for some cases, but this may be far fewer than originally thought.

Whether or not LSV progresses after birth remains unclear, and if so, the variables associated with its progression are unclear. In earlier reports it was suggested that LSV appeared shortly after birth and persisted without evidence of progression or resolution; however, most of these neonates were born at term [4, 5, 9]. Progressive postnatal changes of LSV have been observed in neonates with pulmonary and cardiac diseases [8]. We observed that neonates with LSV on cUS $<15 \mathrm{~d}$ postnatal were more likely to present with Stages 2 and 3 on their initial cUS. This is in contrast to LSV first seen $>15 \mathrm{~d}$ postnatal, when it was more likely to be Stage 1. Only 2/65 neonates showed resolution of LSV by discharge. Of note, neonates who progressed from Stage 0 to $3 \mathrm{LSV}$ were more likely to have evidence of hypothyroidism, which is similar to the observations of Chamnanvanakij et al. in our hospital 18 yrs ago [22]. Both of the neonates that progressed to Stage 3 and had hypothyroidism also had developed BPD. Since only seven neonates progressed to Stage 3, this will require confirmation.

Few investigators have examined the developmental outcome of preterm neonates with LSV. In a recent systematic analysis [47] of long-term outcomes of preterm neonates with LSV, it was concluded that the current literature contained insufficient data to make conclusions since the majority of reports were small, retrospective and contained conflicting conclusions [13, 22, 30]. Further, these studies did not exclude preterm neonates with other intracranial pathology, e.g., ICH and PVL. In the present study, NDI in infants with LSV and no other pathology on cUS did not differ from control infants at $18-36$ mon. They also did not differ from neonates who had other findings on cUS. Thus, the presence of LSV, regardless of the stage, does not portend to worse NDI after correction for GA at birth.

Strengths of this study include its prospective design and effort to reduce the inter-rater variability by designing and validating a new classification system for LSV. The new classification not only improved inter-rater reliability of the diagnosis of LSV on cUS, but also allowed us to define how LSV evolves after birth and to examine the clinical risk factors associated with its progression. The limitation of our study was that our follow-up rate was only $67 \%$ for both infants with LSV and their control group. However, the fact that infants with LSV who completed the follow-up were smaller, younger, and clinically similar to those who were not seen at follow-up could partially mitigate this limitation.

In conclusion, LSV appears to occur in $15 \%$ of the preterm infants $<32 \mathrm{wks}$ GA after implementing a valid and reproducible classification that can be used by the pediatric radiologists. Importantly, LSV may no longer be primarily associated with congenital CMV or other infections, but rather with the development of inflammatory processes; but this will require further study. Finally, we have shown that LSV in the absence of other intracranial pathology is not associated with an increased risk for adverse neurodevelopmental outcomes in preterm infants $<32 \mathrm{wks}$ GA.

Acknowledgements Dr. Rosenfeld was supported by the George L. MacGregor professorship in Pediatrics. No honorarium, grant, or other form of payment was given to anyone to produce the manuscript.

Author contributions JS: Wrote the first draft of the manuscript. She conceptualized and designed the study. She collected and reviewed data from the database, medical records, participated in the interpretation of the data, critically reviewed revisions, and approved the final manuscript. LC: Conceptualized and designed the study. She participated in the interpretation of the data, critically reviewed and approved the manuscript. RH: Conceptualized and designed the study. He participated in the interpretation of the data, follow-up data review and abstraction, critically reviewed and approved the manuscript. MP: Conceptualized and designed the study. She reviewed and classified all the ultrasonograms, without knowledge of prior readings and outcome and participated in data interpretation and critically reviewed the manuscript. DW: Conceptualized and designed the study. She reviewed and classified all the ultrasonograms without knowledge of prior readings and outcome and participated in data interpretation and critically reviewed the manuscript. SB: Conceptualized and designed the study. He completed all statistical analyses, participated in the interpretation of the data, and critically reviewed the manuscript. CR: Conceptualized and designed the study. He participated in the interpretation of the data and critically reviewed, revised and approved the final manuscript.

\section{Compliance with ethical standards}

Conflict of interest The authors declare that they have no conflict of interest.

\section{References}

1. Grant EG, Williams AL, Schellinger D, Slovis TL. Intracranial calcification in the infant and neonate: evaluation by sonography and CT. Radiology. 1985;157:63-8.

2. Teele RL, Hernanz-Schulman M, Sotrel A. Echogenic vasculature in the basal ganglia of neonates: a sonographic sign of vasculopathy. Radiology. 1988;169:423-7. 
3. Cantey JB, Sisman J. The etiology of lenticulostriate vasculopathy and the role of congenital infections. Early Hum Dev. 2015;91:427-30.

4. Ben-Ami T, Yousefzadeh D, Backus M, Reichman B, Kessler A, Hammerman-Rozenberg C. Lenticulostriate vasculopathy in infants with infections of the central nervous system sonographic and Doppler findings. Pediatr Radiol. 1990;20:575-9.

5. Weber K, Riebel T, Nasir R. Hyperechoic lesions in the basal ganglia: an incidental sonographic finding in neonates and infants. Pediatr Radiol. 1992;22:182-6.

6. El Ayoubi M, de Bethmann O, Monset-Couchard M. Lenticulostriate echogenic vessels: clinical and sonographic study of 70 neonatal cases. Pediatr Radiol. 2003;33:697-703.

7. Leijser LM, Steggerda SJ, de Bruine FT, van Zuijlen A, van Steenis A, Walther FJ, et al. Arch Dis Child Fetal Neonatal Ed. 2010;95:F42-6. https://doi.org/10.1136/adc.2009.161935

8. Coley BD, Rusin JA, Boue DR. Importance of hypoxic/ischemic conditions in the development of cerebral lenticulostriate vasculopathy. Pediatr Radiol. 2000;30:846-55.

9. Cabanas F, Pellicer A, Morales C, Garcia-Alix A, Stiris TA, Quero J. New pattern of hyperechogenicity in the thalamus and basal ganglia studied by color Doppler flow imaging. Pediatr Neurol. 1994;10:109-16.

10. Kriss VM, Kriss TC. Doppler sonographic confirmation of thalamic and basal ganglia vasculopathy in three infants with trisomy 13. J Ultrasound Med. 1996;15:523-6.

11. de Vries LS, Beek FJ, Stoutenbeek P. Lenticulostriate vasculopathy in twin-to-twin transfusion syndrome: sonographic and CT findings. Pediatr Radiol. 1995;25:S41-2.

12. Ries M, Deeg KH, Heininger U. Demonstration of perivascular echogenicities in congenital cytomegalovirus infection by colour Doppler imaging. Eur J Pediatr. 1990;150:34-6.

13. Sisman J, Logan JW, Westra SJ, Allred EN, Leviton A. Lenticulostriate vasculopathy in extremely low gestational age newborns: inter-rater variability of cranial ultrasound readings, antecedents and postnatal characteristics. J Pediatr Neurol. 2014;12:183-93.

14. Strand C, Laptook AR, Dowling S, Campbell N, Lasky RE, Wallin LA, et al. Neonatal intracranial hemorrhage: I. Changing pattern in inborn low-birth-weight infants. Early Hum Dev. 1990;23:117-28.

15. Olsen IE, Groveman SA, Lawson ML, Clark RH, Zemel BS. New intrauterine growth curves based on United States data. Pediatrics. 2010;125:e214-24. https://doi.org/10.1542/peds.20090913

16. Duncan AF, Bann C, Boatman C, Hintz SR, Vaucher YE, Vohr $\mathrm{BR}$, et al. Do currently recommended Bayley-III cutoffs overestimate motor impairment in infants born $<27$ weeks gestation? J Pediatr. 2015;35:516-21.

17. Altman DG. Practical statistics for medical Rresearch.. London: Chapman and Hall; 1991.

18. Hughes P, Weinberger E, Shaw DW. Linear areas of echogenicity in the thalami and basal ganglia of neonates: an expanded association. Work Progress Radiol. 1991;179:103-5.

19. Hemachandra AH, Oravec D, Collin M, Tafari N, Mhanna MJ. Early and late postnatal identification of isolated lenticulostriate vasculopathy in preterm infants: associated findings. J Perinatol. 2003;23:20-3.

20. Shefer-Kaufman N, Mimouni FB, Stavorovsky Z, Meyer JJ, Dollberg S. Incidence and clinical significance of echogenic vasculature in the basal ganglia of newborns. Am J Perinatol. 1999;16:315-9.

21. Wang HS, Kuo MF, Chang TC. Sonographic lenticulostriate vasculopathy in infants: some associations and a hypothesis. AJNR Am J Neuroradiol. 1995;16:97-102.
22. Chamnanvanakij S, Rogers CG, Luppino C, Broyles SR, Hickman J, Perlman JM. Linear hyperechogenicity within the basal ganglia and thalamus of preterm infants. Pediatr Neurol. 2000;23:129-33.

23. Makhoul IR, Eisenstein I, Sujov P, et al. Neonatal lenticulostriate vasculopathy: further characterisation. Arch Dis Child Fetal Neonatal Ed. 2003;88:F410-4.

24. Mittendorf R, Covert R, Pryde PG, Lee KS, Ben-Ami T, Yousefzadeh D. Association between lenticulostriate vasculopathy (LSV) and neonatal intraventricular hemorrhage (IVH). J Pediatr. 2004;24:700-5.

25. Paczko N, Rotta NT, Silva A, Leiria F. Hyperechogenicity of thalamic vessels in preterm newborn infants. J De Pediatr. 2002;78:371-4.

26. Kuban K, Sanocka U, Leviton A, Allred EN, Pagano M, Dammann $\mathrm{O}$, et al. White matter disorders of prematurity: association with intraventricular hemorrhage and ventriculomegaly. The Developmental Epidemiology Network. J Pediatr. 1999;134:539-46.

27. Kuban KC, Allred EN, Dammann O, Pagano M, Leviton A, Share $\mathrm{J}$, et al. Topography of cerebral white-matter disease of prematurity studied prospectively in 1607 very-low-birthweight infants. J Child Neurol. 2001;16:401-8.

28. Mittendorf R, Kuban K, Pryde PG, Gianopoulos JG, Yousefzadeh D. Antenatal risk factors associated with the development of lenticulostriate vasculopathy (LSV) in neonates. J Perinatol. 2005;25:101-7.

29. Shin HJ, Kim MJ, Lee HS, Namgung R, Park KI, Lee MJ. Imaging patterns of sonographic lenticulostriate vasculopathy and correlation with clinical and neurodevelopmental outcome. J Clin Ultrasound. 2015;43:367-74. https://doi.org/10.1002/jcu.22196

30. Hong SY, Yang JJ, Li SY, Lee IC. Lenticulostriate vasculopathy in brain ultrasonography is associated with cytomegalovirus infection in newborns. Pediatr Neonatol. 2015;56:408-14. https:// doi.org/10.1016/j.pedneo.2015.04.002

31. Donoghue VGJ, Gormally S, King M. The "candlestick sign" on cerebral sonography: an indication of cerebral asphyxia. Pediatr Radiol. 1990;20:379.

32. de Jong EP, Lopriore E, Vossen AC, Steggerda SJ, Te Pas AB, Kroes AC, et al. Is routine TORCH screening warranted in neonates with lenticulostriate vasculopathy? Neonatology. 2010;97:274-8.

33. Maayan-Metzger A, Leibovitch L, Schushan-Eisen I, Soudack M, Strauss T. Risk factors and associated diseases among preterm infants with isolated lenticulostriate vasculopathy. J Perinatol. 2016;36:775-8.

34. Liao J, Kapadia VS, Brown LS, Cheong N, Longoria C, Mija D, et al. The NLRP3 inflammasome is critically involved in the development of bronchopulmonary dysplasia. Nat Commun. 2015;6:8977 https://doi.org/10.1038/ncomms9977

35. Speer CP. Inflammation and bronchopulmonary dysplasia: a continuing story. Semin Fetal Neonatal Med. 2006;11:354-62.

36. Bhandari V. Postnatal inflammation in the pathogenesis of bronchopulmonary dysplasia. Birth Defects Res A Clin Mol Teratol. 2014;100:189-201.

37. Ryan RM, Ahmed Q, Lakshminrusimha S. Inflammatory mediators in the immunobiology of bronchopulmonary dysplasia. Clin Rev Allergy Immunol. 2008;34:174-90.

38. Neu J, Pammi M. Pathogenesis of NEC: impact of an altered intestinal microbiome. Semin Perinatol. 2017;41:29-35.

39. Nanthakumar N, Meng D, Goldstein AM, Zhu W, Lu L, Uauy R, et al. The mechanism of excessive intestinal inflammation in necrotizing enterocolitis: an immature innate immune response. PLoS ONE. 2011;6:e17776. 10.1371/journal.pone.0017776.

40. MohanKumar K, Namachivayam K, Ho TT, Torres BA, Ohls RK, Maheshwari A. Cytokines and growth factors in the developing intestine and during necrotizing enterocolitis. Semin Perinatol. 2017;41:52-60. 
41. Lamport H, Baez S. Physical properties of small arterial vessels. Physiol Rev Suppl. 1962;5:328-52.

42. Yoshino H, Sakurai T, Oizumi XS, Akisaki T, Wang X, Yokono $\mathrm{K}$, et al. Dilation of perforating arteries in rat brain in response to systemic hypotension is more sensitive and pronounced than that of pial arterioles: simultaneous visualization of perforating and cortical vessels by in-vivo microangiography. Microvasc Res. 2009;77:230-3.

43. Duranovic V, Krakar G, Mejaski-Bosnjak V, Lujic L, Gojmerac T, Marn B. Lenticulostriatal vasculopathy a marker for congenital cytomegalovirus infection? Coll Antropol. 2011;35:149-53.

44. Malinger G, Lev D, Zahalka N, Ben Aroia Z, Watemberg N, Kidron D, et al. Fetal cytomegalovirus infection of the brain: the spectrum of sonographic findings. AJNR Am. J Neuroradiol. 2003;24:28-32.

45. Estroff JA, Parad RB, Teele RL, Benacerraf BR. Echogenic vessels in the fetal thalami and basal ganglia associated with cytomegalovirus infection. J Ultrasound Med. 1992;11: 686-8.

46. Amir J, Schwarz M, Levy I, Haimi-Cohen Y, Pardo J. Is lenticulostriated vasculopathy a sign of central nervous system insult in infants with congenital CMV infection? Arch Dis Child Fetal Neonatal Ed. 2011;96:846-50.

47. Robinson A, Flibotte J, Kaplan SL, DeMauro SB. Lenticulostriate vasculopathy and neurodevelopmental outcomes in preterm infants: a systematic review. Am J Perinatol. 2017;34:780-6. 